\title{
Treatment of the cleft lip and palate patient with few remaining posterior teeth using hybrid telescopic crown denture
}

\author{
Jin-Wook Park, Jin-Hyun Cho* \\ Department of Prosthodontics, School of Dentistry, Kyungpook National University, Daegu, Republic of Korea
}

For individuals with cleft lip and palate, the removable partial dentures (RPDs) have been an important treatment option. Some modifications from conventional prosthetic treatment may be necessary to achieve satisfactory functional and esthetic results in cleft patients. In case of cleft palate patient with periodontally compromised and only posterior few remaining teeth, removable partial prosthesis connected to telescopic crown can be the alternative treatment option. When connected to the RPD, telescopic crowns increase the prosthetic stability and retention, optimize favorable force transmission to the long dental axis, and improve esthetics. And the cross arch stabilization of double crown denture helps to stabilize both divided maxillary ridges in CLP patient. This case present one adult CLP patient using an RPD connected with hybrid telescopic crowns with friction pins to improve not only retention and stability but also aesthetics. (J Dent Rehabil Appl Sci 2017;33(4):284-90)

Key words: cleft lip and palate; friction pin; hybrid telescopic crown RPD

\section{서론}

구순 구개열은 700명 중 한 명에 나타날 만큼 악안면 부위에서 나타나는 가장 흔한 선천적 기형이며 ${ }^{1}$ 당사자 와 가족의 건강, 삶의 질 그리고 사회 경제적 측면에 미치 는 영향이 매우 크다. ${ }^{2}$ 구개열의 원인에는 유전질환 같은 내인성 요인과 기형유발물질과 같은 외인성 요인이 포함 되는데, 외인성 요인에는 흡연, 전신적인 코르티코스테로 이드 호르몬 치료, 마약, 납 중독, 바이러스 질환 그리고 모성영양실조 등을 들 수 있으며, 산모 나이의 증가 또한 구개열 발생의 위험을 증가시킬 수 있다. ${ }^{3}$

최근의 구개열 수술은 악골 발달에 크게 영향을 미치 지 않으며 언어의 정상적인 발달 및 중이염이나 청력장애 의 발생빈도도 줄일 수 있는 생후 10 - 12 개월에 하는 것 이 최근의 경향이다. 그러나 구개열 환자의 경우 다양한

*Correspondence to: Jin-Hyun Cho

Professor, Department of Prosthodontics, School of Dentistry, Kyungpook National University, 2175 Dalgubeol-daero, Jung-gu, Daegu, 41940, Republic of Korea Tel: +82-53-600-7672, Fax: +82-53-427-0778, E-mail: prosth95@knu.ac.kr Received: August 24, 2017/Last Revision: September 17, 2017/Accepted: September 20, 2017
\end{abstract}

정도의 선천적인 상악성장부전이 있으며, ${ }^{4}$ 구개열 및 구 순열을 모두 가지고 있는 경우 구개열만 있는 경우보다 심한 악골성장 장애를 가지고 있다. ${ }^{5.8}$ 또한 수술시기 뿐 아니라 수술 방법, 수술 후 생기는 반흔의 정도 역시 악 골 성장에 영향을 미치고 이로 인해 중안모의 함몰이 나 타나게 된다.

구순구개열의 환자에게 가철성 보철은 중요한 치료선 택 중 하나이다. 구순구개열 환자에게는 여러 수술이 이 루어짐으로 인해 해부학적 및 기능적인 합병증이 야기되 고, 고정성 보철치료나 통상적인 주조 클래스프에 의해 유지되는 국소의치로는 기능적, 심미적으로 만족스러운 결과를 얻지 못할 경우가 있으며, 특히 치주 합병증을 가 진 소수잔존치만 존재하는 경우에는 클래스프 국소의치 의 장기적인 예후를 보장하기 힘들다. 구순구개열로 인 해 구개가 완전히 갈라진 환자에서의 양쪽 치조제를 간

CopyrightC 2017 The Korean Academy of Stomatognathic Function and Occlusion. (c) It is identical to Creative Commons Non-Commercial License. 
접적으로 연결하는 방법으로 이중관 의치를 이용하면 상 악의 안정에 더욱 도움을 줄 수 있고, 치관대치근비가 좋 지 못한 소수 잔존치의 경우에도 성공적으로 치료할 수 있다. ${ }^{9}$

본 증례는 전통적 방법의 가철성 국소의치에서는 사용 하기 힘든 치주질환에 이환된 소수 잔존치(\#16,17, 26) 를 이용하여 구순구개열 환자에서 상악 혼성 이중관 가 철성 국소의치를 제작하여 기능적 및 심미적으로 만족할 만한 결과를 얻었으므로 이를 보고하고자 한다.

\section{증례보고}

본 환자는 37 세 남자환자로 구순구개열 수술 후 보철 치료를 하기 위해 내원하였다. 구강 내 검사 및 방사선학 적 검사에서 \#15부터 \#25까지의 치아가 상실되어 있었 으며, \#16,17, 26, 27도 치주질환에 이환된 상태로 불량 한 치관대치근비를 보였다(Fig. 1A, 1B). 또한 구개열로 인한 상악 전치부 치아 상실과 치조제의 열성장으로 인 해 상순이 후퇴되어 보이는 것을 관찰할 수 있었다(Fig. 2). 하악의 경우 \#33 - 43까지 하악 전치부 치아가 상실 되어 있었으며 하악 임플란트 고정성 보철은 경제적인 이 유로 개인치과의원에서 하길 원했다.
\#16, 17, 26의 경우는 4 - $6 \mathrm{~mm}$ 의 치주낭 깊이와 함께 1 - 2의 동요도를 보여 치주치료를 시행하였으며, \#27의 경우 치주낭 깊이가 $6 \mathrm{~mm}$ 이상, 동요도는 2 이상으로 발 치를 시행하였다.

본 환자의 경우 임플란트를 이용한 고정성 보철물을 하기엔 구개열 부위의 골량이 부족하고 3급 부정교합으 로 인하여 침습적인 골이식술이 필요한 상태였으며, 고정 성 보철물을 이용하여 수복을 하게 될 경우 중안모가 함 몰되어 보이는 것을 적절히 회복할 수 없다고 판단되었 다. 또한 잔존치아를 모두 발치하고 총의치로 수복하는 것도 가능하지만 환자분의 치아를 유지하고 싶은 의지가 매우 강하였으며, 총의치로 수복하였을 경우 의치의 안 정성에 문제가 있을 것으로 예상되었다. 따라서 치주질 환에 이환된 \#16, 17, 26을 지대치로 사용해야 하는 상 황이기 때문에 클래스프 국소의치보다는 마찰핀을 이용 한 혼성 이중관 국소의치를 사용하기로 하였다.

알지네이트(AROMA FINE DF II; GC, Tokyo, Japan)를 사용하여 예비인상을 채득하고 진단모형을 제작 하였으며 상악 개인트레이(Ostron 100; GC)를 제작하 였다. 내관(inner crown)제작을 위해 이미 제작된 개인 트레이에 고무인상재(Aquasil Ultra LV; Dentsply, York, USA)를 사용하여 지대치 인상을 채득하였다(Fig. 3).
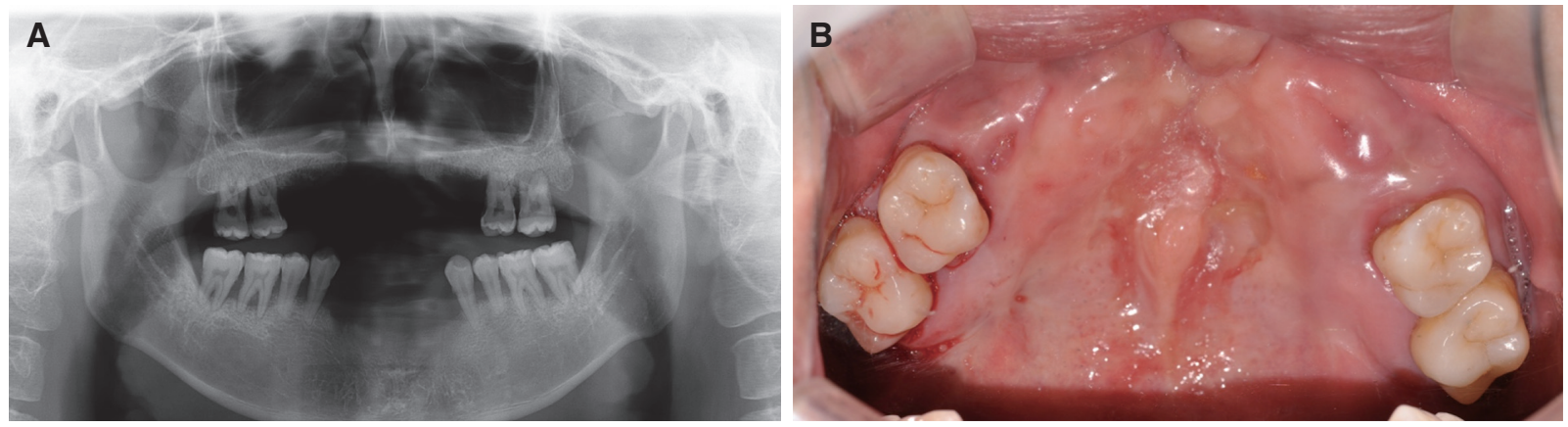

Fig. 1. (A) Initial panoramic radiograph, (B) Initial intraoral photograph, Maxillary occlusal view.

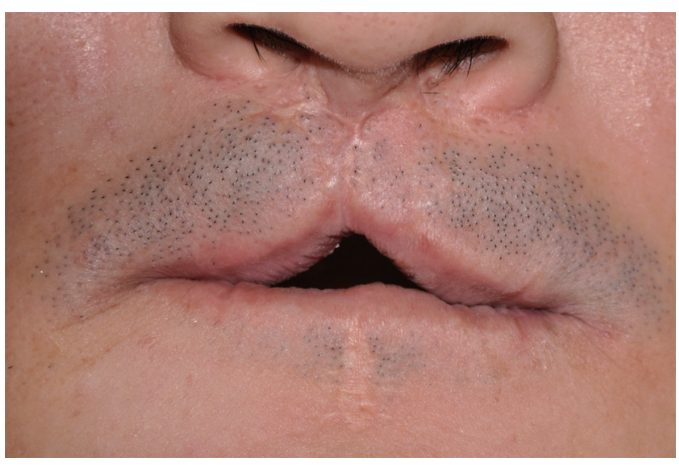

Fig. 2. Extraoral photograph.

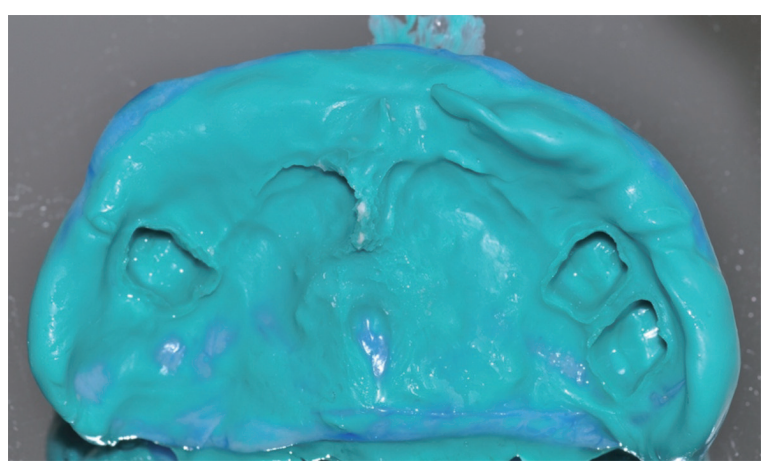

Fig. 3. Maxillary impression for inner crowns. 


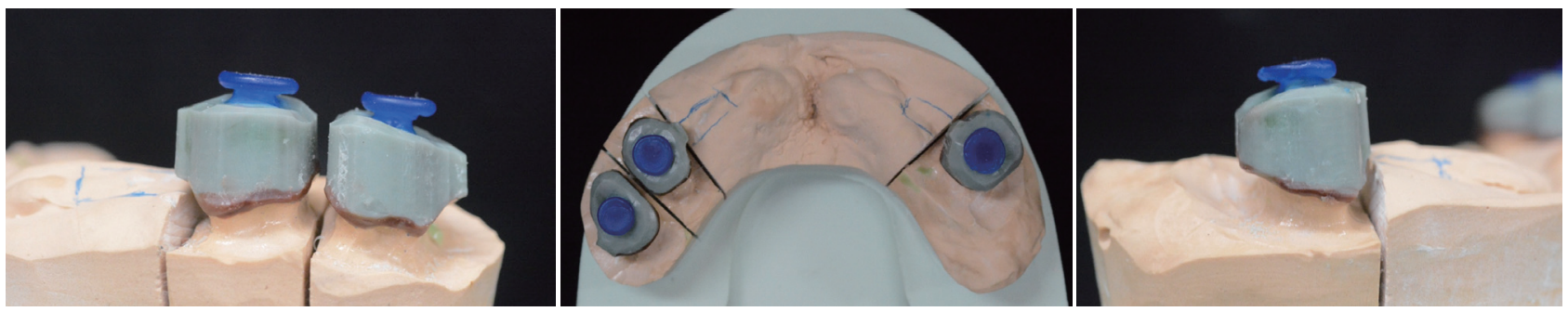

Fig. 4. Wax up for maxillary inner crown.
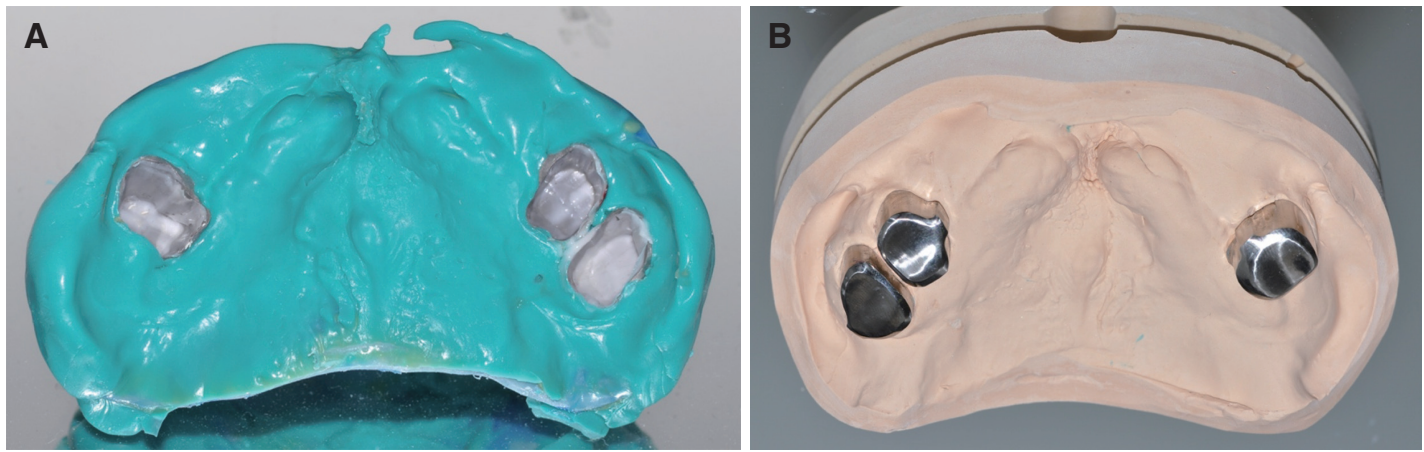

Fig. 5. (A) Maxillary pick up impression, (B) Maxillary master cast.

최종모형에서 내관 제작을 위한 왁스업이 시행되었고, \#16, 26의 근심, \#17의 원심 위치에 마찰핀을 위한 공간 을 부여하였다(Fig. 4).

내관은 코발트크롬합금으로 제작하였다. 내관의 축벽 경사는 $2^{\circ}$ 로 하였으며 경계부위는 샘퍼변연으로 설정하 여 외관의 수직적인 움직임을 허용하지 않도록 하였다. 내관 제작 후 Fit checker ${ }^{\circledR}(\mathrm{GC})$ 를 이용해 구강 내에서 적 합도를 확인하였으며, 모델링 컴파운드(Peri Compound, GC)를 이용해 변연형성을 시행하고 기능인상(Aquasil Ultra LV, Dentsply)을 채득하였다(Fig. 5).

이후 인상체를 이용하여 상악 주모형을 제작하고 내관 연마후 납의치상을 제작하였다. 하악의 경우 개인치과 의원에서 임플란트 식립 후 전치부 임시보철을 해 온 상 태였으며, 이 상태에서 교합고경과 중심위를 채득한 후 (Fig. 6) 교합기에 모형을 부착하였다.

그 후 상악 지대치의 외관 제작을 위해 내관 위로 왁스 업을 시행한 후 코발트크롬합금(VeraBond ${ }^{\circledR} 2 \mathrm{~V}$, Aalbadent, Fair field, USA)으로 주조하여 외관을 완성하였다 (Fig. 7).

구개판형 연결장치를 제작한 후 레이저용접을 이용하

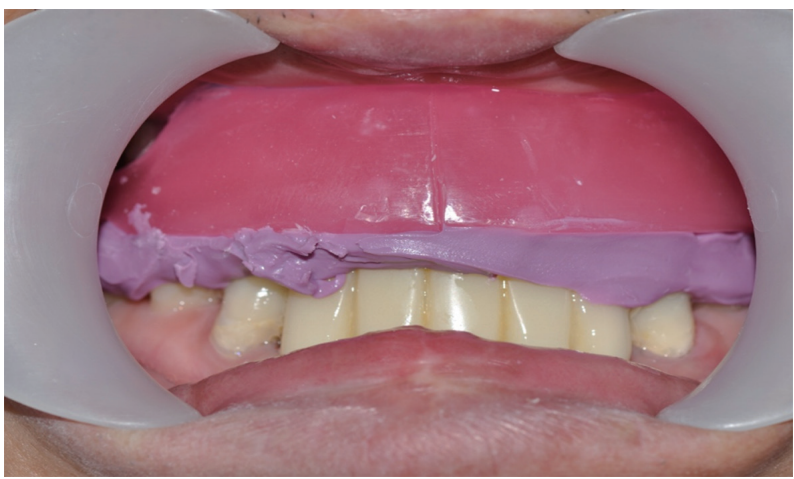

Fig. 6. Bite registration with conventional method.

여 외관을 연결하였으며, 외관과 내관의 유지력을 위해 마찰핀을 외관에 연결하였다. 이 방법은 $0.8 \mathrm{~mm}$ 구리봉 으로 내관과 외관사이에 각 $0.4 \mathrm{~mm}$ 정도의 공간을 만들 고, 여기에 $0.8 \mathrm{~mm}$ 의 마찰핀을 삽입하여 외관에 핀을 레 이저용접으로 고정하게 된다. 내관과 외관 제작을 비귀 금속으로 제작하기 때문에 산화막이 생기고, 이를 제거 함으로써 생기는 공간 때문에 발생하는 유지력의 상실을 보상하기 위해서 마찰핀을 이용한다. 

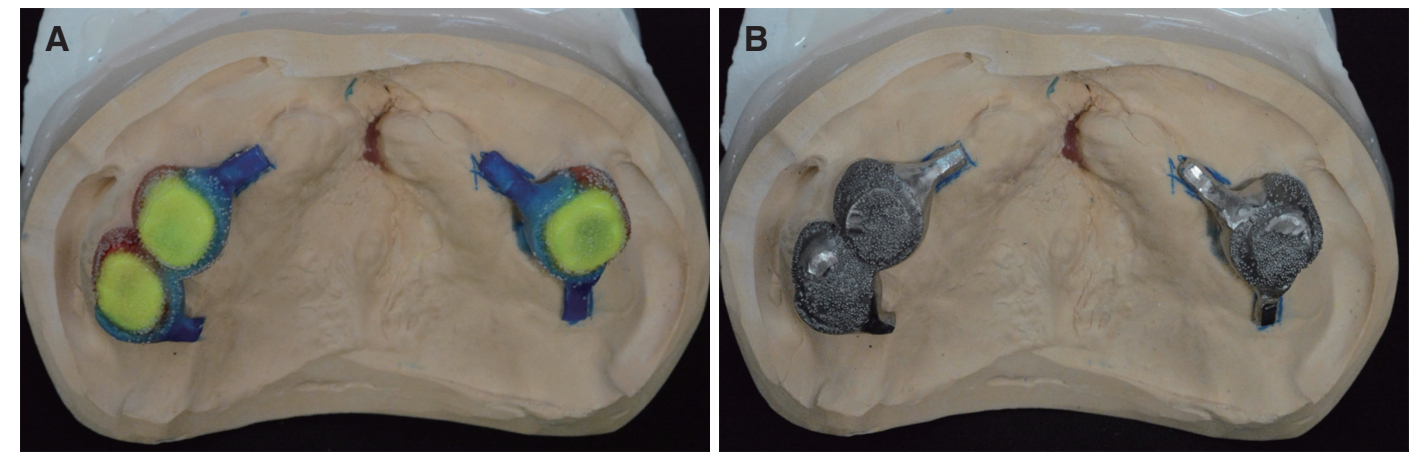

Fig. 7. (A) Wax up for maxillary outer crown, (B) Co-Cr alloy outer crown.
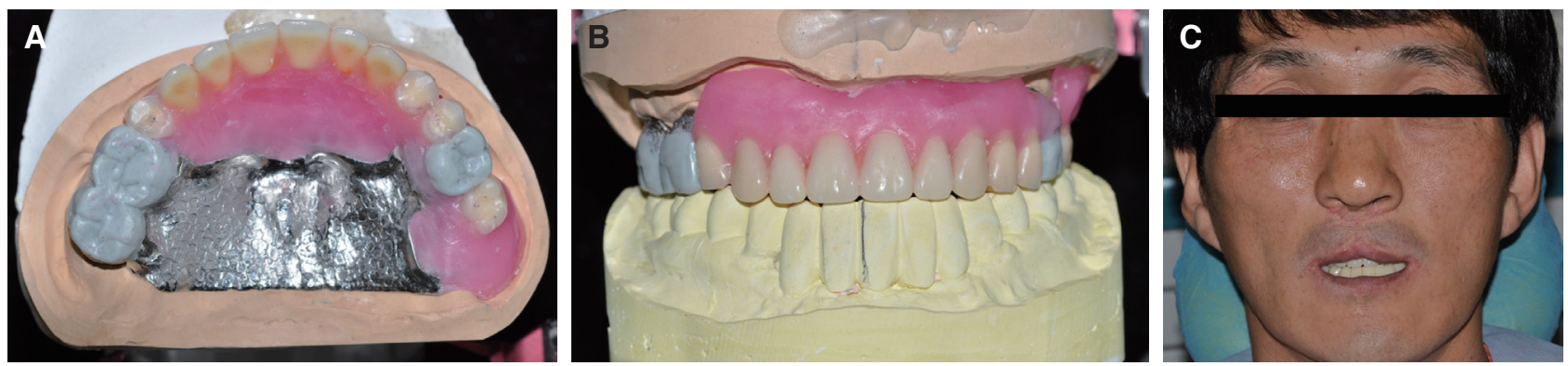

Fig. 8. (A) Maxillary Wax denture occlusal view, (B) Frontal view, (C) Wax denture try-in.
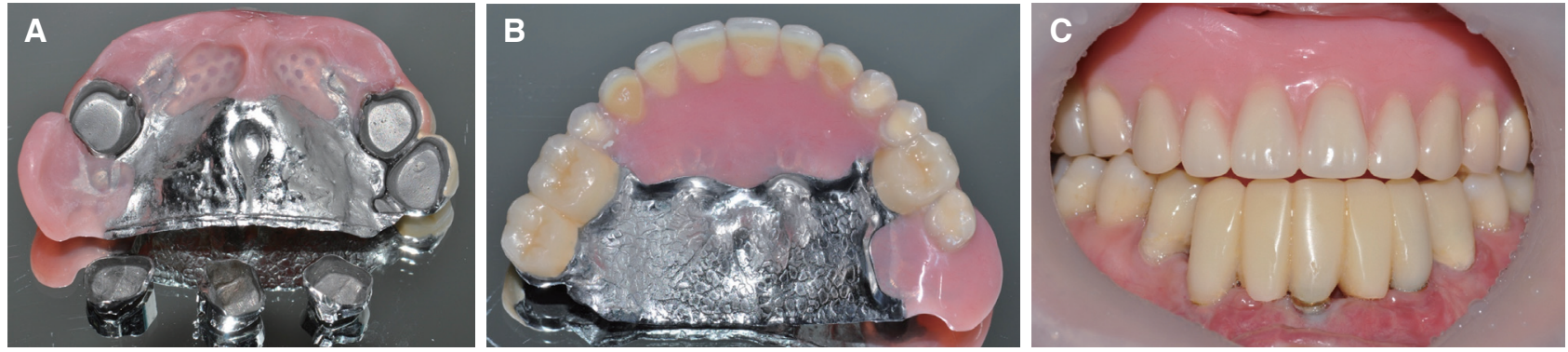

Fig. 9. (A), (B) Maxillary double crown RPD, (C) Delivery of maxillary RPD.

외관에 왁스업을 시행하고 상악 납의치를 제작한 후 (Fig. 8A, 8B) 환자의 구강 내에서 시적 및 수정이 이루어 졌다(Fig. 8C).

중심위 교합을 확인하고 가능한 양측성 균형교합을 부 여하기 위해 노력하였다. 상순부위의 심미적인 회복이 이 루어진 것을 확인할 수 있었다. 납의치 시적한 것을 기준 으로 의치를 온성하고 외관 부위에는 Sinfony ${ }^{\mathrm{TM}}$ 를 이용 하여 완성하였다(Fig. 9).

현재 6개월 점검이 이루어졌으며 지대치의 상태 및 의 치의 지지 및 유지가 양호하였다. 앞으로 정기적인 관찰 을 통한 유지 및 관리가 필요한 것으로 보인다.

\section{고찰}

구순구개열 환자의 보철수복 방법에는 여러 가지가 있 는데, 본 증례에서는 이중관 의치를 통하여 교합 및 입술 지지 회복을 얻고자 하였다. 이런 이중관 의치의 장점으 로는 환자에 의한 구강 위생의 접근성의 용이함, 지대치 에 가해지는 측방력의 감소, 개개 지대치의 독립성, 고정 성 보철에서는 사용하지 말아야 할 예후가 의심스러운 지대치의 사용 가능성, 횡단치열궁안정, 광범위한 치조 골 소실 환자에서의 심미적인 대체 등을 들 수 있다. ${ }^{10}$ 특 히 본 증례에서는 치주질환에 이환되어 고정성 또는 클 
래스프 가철성 국소의치에서 예후가 의심스러울 수 있는 소수 잔존치를 지대치로 사용하여 이중관 의치를 제작한 것에 의미가 있다. 이중관 의치를 사용하여 지대치에 측 방력이 아닌 수직력이 작용함으로써 소수 잔존치에 있어 서도 좋은 결과를 보여준다. 만약 지대치의 상실이 일어 나더라도 이중관 의치의 특성상 적은 비용으로 쉬운 수 리가 가능하기 때문에 치주질환에 이환된 치아를 지대치 로 사용하는 것에 대한 장점이 있다. ${ }^{11}$

이중관 시스템은 각각 다른 유지 기전에 의해 구별된 다. ${ }^{12}$ Telescopic 크라운은 내관과 외관의 평행한 면의 마 찰을 통해 유지를 얻는 방식이다. Conical 크라운 또는 tapered telescopic 크라운은 완전히 안착되었을 때 쐐 기 효과를 이용한 마찰을 통해 유지를 얻는 방식으로, 쐐 기 효과의 크기는 내관의 수렴각에 의해 결정이 되는데 수렴각이 작을수록 더 큰 유지를 얻게 된다. 마지막으로 공간 적합(clearance fit)을 이용한 이중관 방식인데 혼 성 이중관(hybrid telescopic crown 또는 hybrid double crown)으로도 불리며 삽입 또는 철거 시 마찰이나 쐐기 효과를 이용하는 것이 아닌 추가적인 어태치먼트나 기능 적으로 형성된 의치의 변연에 의해 유지력을 얻는다.

Telescopic과 conical 크라운 두가지 방식 모두 탈착 과 정에 의해 발생하는 금속의 마모로 인해 유지력이 감소 되기 쉬우며, 이런 경우 유지력을 회복하기가 힘들다. 또 한 이들은 고정된 지지를 제공하기 때문에 교합력이 가 해졌을 때 교합면 방향으로의 움직임이나 교합력이 제거 되었을 때의 반대방향으로의 움직임을 허락하지 않으므 로, 소수 잔존치를 이용하여 의치를 제작할 경우에 지대 치 동요도의 증가나 조기 치아상실을 야기할 수 있다. 이 에 반해 혼성 이중관의 경우 추가적인 어태치먼트를 이 용하므로 유지력의 감소가 나머지 두 방법에 비해 매우 적다. 또한 내관과 외관 사이에 $0.3-0.5 \mathrm{~mm}$ 정도의 공 간을 부여하여 탄성 지지를 제공함으로써 의치의 움직임 을 허용하고, 지대치에 가해지는 유해한 힘이 줄어들어 지대치의 유지에도 도움이 된다.

본 증례에서 사용된 이중관 의치는 마찰핀을 이용한 혼성 이중관 가철성 국소의치로, 마찰핀을 위한 공간은 방전가공법(spark erosion)을 통하여 제작하게 된다. 방 전가공법은 외관의 마찰핀을 받아들이는 작은 통로를 위 한 평행한 인접면 만을 필요로 하기 때문에 내관의 부피 를 줄여주고, 줄어든 내관의 부피로 인해서 외관을 더욱 심미적이며 위생적으로 제작할 수 있는 공간을 얻게 된 다. ${ }^{13}$ 또한 마찰핀을 이용해 유지력의 조정이 가능하며 핀
이 파절되었을 경우에도 수리가 쉽다. 이 마찰핀을 이용 한 혼성 이중관 가철성 국소의치는 의치의 유지와 지지 를 향상시키고, 그 결과로 구순구개열로 인한 유지력의 감소를 극복할 수 있었다.

이중관 의치의 좋은 예후를 위해서는 몇가지 요소들이 고려되어야 하는데, 특히 횡단치열궁안정이 의치의 수명 에 중요한 요소로 작용한다. 하지만 기능인상이 적절히 채득되지 않으면 과도한 측방력이 지대치에 가해지게 되 므로 적절한 기능인상과 정기적인 점검을 통한 첨상이 필 요할 것으로 생각된다.

\section{결론}

본 증례를 통하여 치주질환에 이환된 소수 잔존치를 갖는 구순구개열 환자에서 이중관 의치를 제작하여 기능 적, 심미적으로 만족스러운 결과를 얻을 수 있었으며, 이 중관 의치가 이러한 선천적 기형 및 치주적으로 예후가 불량한 치아를 가지는 환자에서 좋은 치료대안이 될 것 이라 여겨진다. 현재 6 개월 점검에서 지대치 및 의치의 양 호한 상태를 확인할 수 있었으며, 앞으로 정기적인 유지 및 관리가 필요할 것으로 사료된다.

\section{Acknowledgements}

This Research was supported by Kyungpook National University Research Fund, 2016.

\section{ORCID}

Jin-Hyun Cho https://orcid.org/0000-0002-2453-9372

Jin-Wook Park https://orcid.org/0000-0002-7863-1449

\section{References}

1. Dixon MJ, Marazita ML, Beaty TH, Murray JC. Cleft lip and palate: understanding genetic and environmental influences. Nat Rev Genet 2011;12:16778.

2. Palmeiro MR, Piffer CS, Brunetto VM, Maccari PC, Shinkai RS. Maxillary rehabilitation using a removable partial denture with attachments in a cleft lip and palate patient: a clinical report. J Prosthodont 2015;24:250-3. 
3. Balkaya MC, Sultan H, Erdem S, Mutlu D. Prosthetic rehabilitation of a patient with a unilateral cleft palate: a clinical report. J Prosthet Dent 2014; 111:269-72.

4. Bishara SE, de Arrendondo RS, Vales HP, Jakobsen JR. Dentofacial relationships in persons with unoperated clefts: comparison between three cleft types. Am J Orthod 1985;87:481-507.

5. Oiler DK, Wieman LA, Doyle WJ, Ross C. Infant babbling and speech. J Child Lang 1976;3:1-11.

6. Krogman WM, Mazaheri M, Harding RL, Ishiguro K, Bariana G, Meier J, Canter H, Ross P. A longitudinal study of the craniofacial growth patterns in children with clefts as compared to normal, birth to six years. Cleft Palate J 1975;12:59-84.

7. Schweckendiek W, Doz P. Primary veloplasty: long term results without maxillary deformity: a twentyfive year report. Cleft Palate J 1978;15:268-74.

8. Pearl RM, Kaplan EN. Cephalometric study of facial growth in children after combined pushback and pharyngeal flap operations. Plast Reconstr Surg
1976;57:480-3.

9. Cho JH, Cho SA. The use of telescopic crowns in removable partial denture treatment for patients with severe periodontal disease: two patient case history reports. Int J Prosthodont 2016;29:175-8.

10. Breitman JB, Nakamura S, Freedman AL, Yalisove IL. Telescopic retainers: an old or new solution? A second chance to have normal dental function. J Prosthodont 2012;21:79-83.

11. Wöstmann B, Balkenhol M, Weber A, Ferger P, Rehmann P. Long-term analysis of telescopic crown retained removable partial dentures: survival and need for maintenance. J Dent 2007;35:939-45.

12. Wenz HJ, Lehmann KM. A telescopic crown concept for the restoration of the partially edentulous arch: the Marburg double crown system. Int J Prosthodont 1998;11:541-50.

13. Weber H, Frank G. Spark erosion procedure: a method for extensive combined fixed and removable prosthodontic care. J Prosthet Dent 1993;69: 222-7. 


\section{치주질환에 이환된 소수 잔존치를 가지는 구순구개열 환자에서의 상악 혼성 이중관 의치를 이용한 수복증례}

박진욱, 조진현*

경북대학교 치과병원 치과보철과

구순구개열 환자에게 가철성 보철치료는 중요한 치료 선택 중 하나이다. 구순구개열 환자에서 만족스러운 기능적 및 심 미적 결과를 얻기 위해서는 전통적인 보철 치료법에서 약간의 수정이 필요할 수 있는데, 치주 질환에 이환되어 있으며 소 수의 구치만 잔존해 있는 구개열 환자의 경우 이중관에 연결된 가철성 보철이 치료 선택의 대안이 될 수 있다. 이중관이 가철성 국소의치에 연결되면 보철적 안정성과 유지를 증가시키고 치아 장축에 유리한 힘 전달을 최적화하며 심미성도 향 상시킨다. 그리고 이중관 의치의 횡단치열궁안정(cross arch stabilization)은 구순구개열 환자의 갈라진 치조제의 안정화 에도 도움을 준다. 본 증례는 성인 구순구개열 환자에서 마찰핀(friction pin)을 사용한 혼성 이중관 가철성 국소의치를 제작하여 유지 및 안정성과 함께 심미성도 향상시켜 만족할 만한 결과를 나타낸다.

(구강회복응용과학지 2017;33(4):284-90)

주요어: 구순구개열; 마찰핀; 혼성 이중관 가철성 국소의치

*교신저자: 조진현

(41940) 대구광역시 중구 달구벌대로 2175 경북대학교 치과병원 치과보철과

Tel: 053-600-7672 | Fax: 053-427-0778 | E-mail: prosth95@knu. ac. kr

접수일: 2017년 8월 24일 | 수정일: 2017년 9월 17일 | 채택일: 2017년 9월 20일 